\title{
Molecular Dynamics Simulations of p97 Including Covalent, Allosteric and ATP-Competitive Inhibitors
}

\author{
Stefano Rendine, ${ }^{1, \dagger}$ Christian Orrenius, ${ }^{2, \star}$ Federico Dapiaggi, ${ }^{1,3}$ \\ Stefano Pieraccini, ${ }^{1,3}$ Ilaria Motto, ${ }^{2}$ Roberto D'Alessio, ${ }^{2}$ Paola Magnaghi, ${ }^{2}$ \\ Antonella Isacchi, ${ }^{2}$ Eduard Felder ${ }^{2}$ and Maurizio Sironi ${ }^{1,3, *}$ \\ ${ }^{1}$ Dipartimento di Chimica, Università degli Studi di Milano, Via Golgi 19, Milano, Italy \\ ${ }^{2}$ Business Unit Oncology, Nerviano Medical Sciences, 20014 Nerviano, Italy \\ ${ }^{3}$ Consorzio Interuniversitario Nazionale per la Scienza e Tecnologia dei Materiali (INSTM), UdR Milano \\ ${ }^{\dagger}$ Syngenta Crop Protection AG, Crop Protection Research, Schaffhauserstrasse, CH-4332 Stein, Switzerland \\ *Corresponding author: E-mail: christian.orrenius@nervianoms.com,maurizio.sironi@unimi.it
}

Received: 11-28-2018

\begin{abstract}
Binary (nucleotide-protein dimer and hexamer complexes) and ternary (nucleotide-protein-inhibitor complexes) p97 complexes were subjected to molecular dynamics simulations in an attempt to further our understanding of the p97 protein oligomer domain stability and, more importantly, of the recently reported diverse molecular mechanisms of inhibition including allosteric, ATP-competitive and covalent inhibitors. Analysis of stable states following equilibration phases indicated a higher intrinsic stability of the homohexamer as opposed to the dimer, and of N-D1 domains as opposed to the D2 domain. The molecular dynamics of the proposed allosteric binding model reproduced important molecular interactions identified experimentally with high frequency throughout the trajectory. Observed conformational changes occurring in the D2 nucleotide binding site provided a novel bind-rearrange-react hypothesis of stepwise molecular events involved in the specific covalent inhibitor mode of action.
\end{abstract}

Keywords: Drug design; protein-protein interaction; mm-pbsa; molecular dynamics

\section{Introduction}

The AAA+ (ATPases Associated with diverse cellular Activities) protein family carries out multiple functions, including chromatin decondensation, homotypic membrane fusion and ubiquitin dependent protein degradation by the proteasome. In particular, p97, or Valosine-containing Protein (VCP), is a $97 \mathrm{kDa}$ protein belonging to the AAA+ protein family. p97 includes two copies of a nucleotide-binding domain, called D1 and D2 which are interconnected by a 20 amino-acids long loop (the D1-D2 linker) and preceded by a non-nucleotide binding domain, the $\mathrm{N}$-domain, which is oriented outward to permit interaction with adapter proteins. ${ }^{1}$

p97 regulates a number of processes involving ubiquitin, due to its ability to segregate ubiquitinated substrates from unmodified partners. In particular, p97 plays an essential role in the ubiquitin-dependent proteasomal degradation, including endoplasmic reticulum-associated degradation (ERAD), ${ }^{2,3}$ degradation of some cytosolic proteins by the ubiquitin-fusion domain (UFD) pathway ${ }^{4}$ and rapid degradation of nascent peptides during heat shock. ${ }^{5}$

Crystallographic studies of $\mathrm{p} 97^{6}$ testify that it functions as a homo-hexameric ring, formed by the D1 and D2 domains with the $\mathrm{N}$-terminal domain oriented outward to permit interaction with adapter proteins. The formation of this complex molecular machinery is driven by protein-protein interactions (PPIs).

In recent works, ${ }^{7-9}$ small molecules able to inhibit p97 were identified (Figure 1a). Different mechanisms of inhibition were proposed for these molecules. NMS-873 seems to act as an allosteric inhibitor of p97, binding in 
close proximity to the N-terminal of the D1-D2 linker. NMS-322 is a ATP competitor and binds in the nucleotide binding site in D2. Finally, NMS-859 is a covalent inhibitor that binds to Cys522. However, there is a lack of structural models rationalizing these postulated binding modes. In this work we employ computational techniques to investigate the binding mode of these inhibitors both from the conformational and energetical point of view. Molecular dynamics simulations were carried out on these systems and a subsequent computational alanine scanning allowed us to identify the fundamental residues for the binding of these compounds. The aforementioned technique has been extensively used to map, from the energetic point of view, the interaction pattern of protein in complex with small ligands both of peptidic ${ }^{10}$ and non-peptidic ${ }^{11}$ nature. In the case of the allosteric inhibitor (NMS-873) the need of a good starting structure for molecular dynamics simulations prompted us to employ molecular docking. It is well proven in literature, indeed, that molecular docking studies on biological systems can successfully predict the structures of intermolecular complexes formed by ligands and their receptors (ranging from proteins ${ }^{12}$ to $\mathrm{DNA}^{13}$ ).

\section{Materials and Methods}

The reference $\mathrm{p} 97$ structure was obtained from the Protein Data Bank (PDB ID code: 3CF1).The VCP hexamer, the relevant biological assembly according to the authors of the original paper ${ }^{1}$ (as well as an analysis performed with the software PISA ${ }^{14}$ ), was derived from standard symmetry operations in PyMOL. ${ }^{15}$ The missing residues in the D2 domain were rebuilt using the software Modeller 9v7. ${ }^{16}$ Molecular dynamics simulations were carried out with Gromacs 4.5.3 ${ }^{17}$ using the Amber ff99SB ${ }^{18}$ force field for the protein and the Generalized Amber Force Field $(\mathrm{GAFF})^{19}$ for the inhibitors and nucleotides. The complexes were solvated with TIP3 $\mathrm{P}^{20}$ waters and neutralized with sodium ions.

The molecular systems studied were first subjected to a steepest descent minimization run (10000 steps) with alpha carbons constrained by a force constant of $1000 \mathrm{~kJ}$ $\mathrm{mol}^{-1} \mathrm{~nm}^{-2}$. Subsequently, an equilibration of $200 \mathrm{ps}$ was performed under NVT conditions at $310 \mathrm{~K}$ using the v-rescale thermostat ${ }^{21}$ with a time constant of $0.1 \mathrm{ps}$. Electrostatic interactions were treated with the Particle Mesh Ewald $(\mathrm{PME})^{22}$ algorithm using a $10 \AA$ cutoff. All bonds were constrained using the $\mathrm{LINCS}^{23}$ algorithm, allowing a 2 fs timestep. A further 200 ps equilibration run was performed under NPT conditions at $310 \mathrm{~K}$ and $1 \mathrm{~atm}$ using the Berendsen barostat method ${ }^{24}$ with a 0.5 ps correlation time. Alpha carbons were kept constrained as above. A 20 ns production run followed at constant temperature and pressure (1 atm, $310 \mathrm{~K}$ ), releasing the constraints on the alpha carbons.

In order to clarify relative importance of amino acid residues and their interactions, computational alanine scanning and free energy calculations were performed using the Molecular Mechanics Generalized Born Surface Area (MM-GBSA) approach ${ }^{25}$ on snapshots extracted at $20 \mathrm{ps}$ intervals from the last $10 \mathrm{~ns}$ of the trajectories (500 snapshots in total) once the systems reached equilibrium. A $0.15 \mathrm{M} \mathrm{NaCl}$ solution was simulated as the solvent. The entropic contribution to the free energy data was neglected in the free energy calculations used in this study mainly due to the lack of reliability of results for the molecular systems considered here. An extended discussion on this topic can be found in literature. ${ }^{26-30}$

The starting structures of the complexes containing the inhibitor molecules NMS-873, NMS-322 and NMS859 (non covalently bound, see discussion) were generated by molecular docking with QXP v0705 program ${ }^{31}$ setting the following parameters to the mcdock tool: in house modified QXP MacroModel forcefield, 1500 Monte Carlo steps saving 20 poses for visual inspection. The rather large number of poses saved enabled a procedure identifying orientations compatible with photo-affinity labeling experimental evidence reported by Magnaghi et al., 2013. ${ }^{7}$ Candidate binding sites were studied in order to identify pockets suitable for hosting inhibitor substituents. According to standard modeling procedures, binding site side chains were scrutinized in order to address protonation and $180^{\circ}$ rotations of crystallographically equivalent groups and correct eventual atomic overlap. Subsequently, all structures were subject to the pre-simulation and simulation phases described above.

The Cys522/NMS-859 covalently bound structure was prepared as follows. As the p 97 crystal structure shows the side chain of Cys522 (covalent bond site) completely buried, the dynamical behaviour of the Walker A loop was evaluated with a $20 \mathrm{~ns}$ long MD simulation of the apo hexamer protein to verify if a suitable conformation of Cys522 side chain exists for the reaction with NMS-859. The change in the surface accessible area of Cys522 was monitored and, interestingly, Cys522 was found to protrude into the ATP binding site in a solvent accessible conformation during the simulation. The protomer showing the highest solvent accessible area for Cys522 was extracted with its adjacent protomer and a relevant structural model of NMS- 859 covalently bound to the Cys522 side chain was obtained building the Cys522/NMS-859 bond.

A more energetically meaningful structure was sought for by subjecting this new model to 100 simulated annealing runs, raising the temperature to $600 \mathrm{~K}$ and then cooling down to $0 \mathrm{~K}$. Even at high temperatures, NMS-859 did not undergo any major rearrangements within the binding site. A reference structure was obtained by performing a cluster analysis on the 100 final structures of the simulated annealing and choosing the central element of the most populated cluster. The structure resulting from the cluster analysis was used to generate the hexamer with a NMS-859 molecule bound in each of the D2 ATP binding sites. The hexamer was subsequently submitted to a $20 \mathrm{~ns} \mathrm{MD}$ simulation. 


\section{Results and Discussion}

A series of molecular dynamics simulations was performed on a p97 hexamer model in complex with NMS873, NMS-322 and NMS-859 (Figure 1). Before doing so, we compared results from simulations performed on dimeric $v s$ hexameric forms of $\mathrm{p} 97$ without inhibitors. The use of a dimeric in the place of the hexameric model constituted a significant advantage in terms of CPU-time required for these calculations. However, results from the test simulations excluded this possibility due to severe molecular instability observed with the dimer. Specifically, unlike the hexameric system, the p97 dimer suffered a gradual but complete detachment of the D2 domain from the $\mathrm{D} 1$ domain within the same protomer in the early stages of the production run. Such a dramatic rearrangement would interfere with the simulation of our set of ligands, which bind regions at the intra- and inter-protomer interfaces.

The allosteric binding site and NMS-873. NMS-873 was originally docked into a putative binding site that was subsequently confirmed by photo-affinity labeling experiments. Depending on the position of reactive groups on NMS-873 analogues, Lys615 and Asn616 were specifically targeted as previously reported. ${ }^{11}$ The model was further refined according to the procedure in the material and methods section. The selected pose involved, among other pockets, the lateral tunnel leading to the central pore of the hexamer between the D1 and D2 domains of two adjacent protomers. On the basis of observed kinetics, a stoichiometry of 1:2 was applied with one molecule bound to the $\mathrm{A}-\mathrm{B}, \mathrm{C}-\mathrm{D}$ and $\mathrm{E}-\mathrm{F}$ interfaces, respectively.

$\Delta G$ and alanine scanning. The three NMS- $873 \mathrm{~mol}-$ ecules showed a consistent behaviour throughout the molecular dynamics run, with a $\Delta \mathrm{G}$ of binding of $-69.2 \pm 3.1$ $\mathrm{kcal} / \mathrm{mol}$ (A-B interface), $-67.8 \pm 2.7 \mathrm{kcal} / \mathrm{mol}$ (C-D interface) and $-71.5 \pm 2.9 \mathrm{kcal} / \mathrm{mol}$ (E-F interface). The coherent results for the three molecules are likely to be due to the tight packing and good fit of the molecule among residues and cavities at the D1 and D2 interface of the two adjacent protomers. In this case, the use of a hexameric model system turned out to be particularly important, since the simulation of the dimer would have led to a slacker binding site and a progressive weakening of the network of interactions due to protomer separation.

Computational alanine scanning highlighted the most relevant protein residues involved in the binding of this inhibitor. Lys615 showed the highest $\Delta \Delta G$ values on average $(4.4 \mathrm{kcal} / \mathrm{mol})$ with its contribution consisting of both hydrophobic interactions with the biphenyl moiety of NMS-873 and the hydrogen bond between the $\varepsilon$-amino group and the pyridine moiety of the inhibitor. This particular hydrogen bond occurred in $20 \%, 34 \%, 71 \%$ of the snapshots in the A-B, C-D, E-F binding sites, respectively. The difference was due to the possible torsion of the pyridine moiety with respect to the triazole plane, allowing
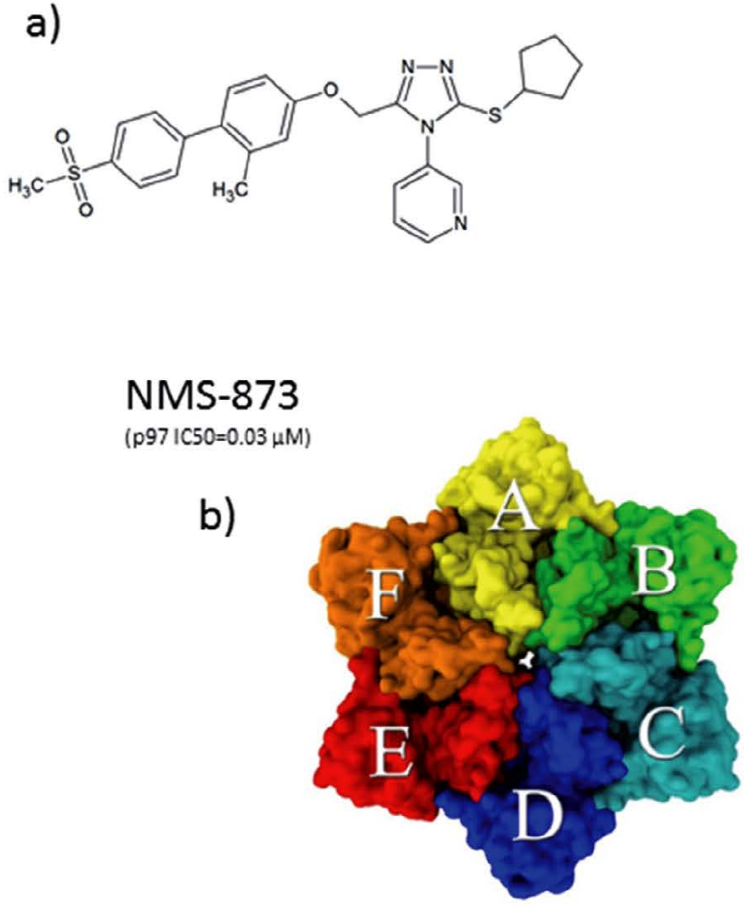<smiles>Nc1ccc(-c2cc(-c3ccccc3)nc(NC3CCC(C(=O)O)CC3)n2)cc1[N+](=O)[O-]</smiles><smiles>O=C(CCl)Nc1cccc(NC2=NS(=O)(=O)c3ccccc32)c1</smiles>

NMS-322

NMS-859

(p97 IC50 $=0.05 \mu \mathrm{M})$ $(\mathrm{p} 97 \mathrm{IC} 50=0.37 \mu \mathrm{M})$

Figure 1.a) Structures of NMS-873, NMS-322 and NMS-859. b) Top view of the p97 hexamer: the single protomers are labelled with letters from A to F. c) Lateral view of the $\mathrm{p} 97$ hexamer coloured by domains and highlighting the NMS-873 binding site (red rectangle). 
considerable variability in the making and breaking of this interaction. The aromatic pyridine ring was also found to effectively interact with Gln568 $(1.3 \mathrm{kcal} / \mathrm{mol})$ through van der Waals contacts.

Gln215 (2.9 kcal $/ \mathrm{mol})$, Gln212 $(1.0 \mathrm{kcal} / \mathrm{mol})$ and Leu $456(1.6 \mathrm{kcal} / \mathrm{mol})$ further stabilized the binding at the opposite ends of the molecule through hydrophobic contacts with the cyclopentyl and the methylsulphonyl group. Most relevant interactions are shown in Figure 2a.

Other less frequent examples of amino acids that favourably took part in the binding with NMS-873, showing higher $\Delta \Delta \mathrm{G}$ values only in specific couples of protomers were $\operatorname{Arg} 453$ (1.3 kcal/mol, A-B interface) and His406 (2.0 $\mathrm{kcal} / \mathrm{mol}, \mathrm{B}-\mathrm{C}$ interface). Both formed hydrogen bonds with the terminal $p$-methylsulphonyl moiety. Gln458 (1.2 $\mathrm{kcal} / \mathrm{mol})$ and Asn460 (1.7 kcal/mol) participated in stabilizing the biphenyl part of the molecule in the $\mathrm{C}-\mathrm{D}$ couple. Further hydrophobic interactions involved Arg365 (2.0 $\mathrm{kcal} / \mathrm{mol}, \mathrm{A}-\mathrm{B}$ couple) and Lys211 (2.0 kcal/mol, E-F couple), which make favourable contact with the pyridine and the cyclopentyl moieties, respectively.

ATP-competitive inhibitors. NMS-322 belongs to the class of compounds sensitive to the ATP concentration. ${ }^{13}$ Due to the complex and cooperative enzymatic mechanism of $\mathrm{p} 97$, it is impossible to distinguish between direct ATP competition and a mixed inhibitory mechanism where the binding of the compound affects the binding affinity of ATP in a different pocket of the hexamer. However, also in this case, there is experimental evidence of direct interactions within the nucleotide binding site in D2, namely the binding of Asp478 with a reactive azido analog of NMS-322 ("compound 35"). ${ }^{13}$

$\Delta \mathbf{G}$ and alanine scanning. Computational alanine scanning was performed to highlight the residues providing the principal interactions in NMS-322 binding. The results identified Thr525, Leu526 and Thr688 as the most important residues in all six protomers (Figure 2b). Leu526 showed the highest average $\Delta \Delta \mathrm{G}$ value $(2.5 \mathrm{kcal} / \mathrm{mol})$ establishing hydrophobic interactions with the nitroaniline and the cyclohexane moieties of NMS-322. Thr688 (average $\Delta \Delta \mathrm{G}$ of $1.1 \mathrm{kcal} / \mathrm{mol}$ ) provided further hydrophobic interactions, whereas Thr525 (average $\Delta \Delta G=1.3 \mathrm{kcal} /$ mol) engaged hydrogen bonds with the carboxyl group of NMS-322, both through the backbone (44\%) and the sidechain $(52 \%)$.

Other aminoacids displayed varying $\Delta \Delta \mathrm{G}$ values depending on the specific protomer, indicating some freedom of translation within this relatively large binding site. In particular, a group of residues in common for protomers $\mathrm{A}, \mathrm{B}, \mathrm{D}$ and $\mathrm{E}$ with cross-protomer interactions was identified. Only for these protomers, Arg635 showed average $\Delta \Delta \mathrm{G}$ values of $1.7 \mathrm{kcal} / \mathrm{mol}$, providing interactions with the hydrophobic part of NMS-322 and hydrogen bonds with the carboxylic moiety. Hydrogen bonding was relatively often observed in protomers A ( $25 \%$ frequency) and E (15\%). For the same group of NMS-322 molecules, the carboxylic substituent frequently made interactions with Lys524. The molecules bound to protomer $\mathrm{C}$ and $\mathrm{F}$ exhibited a slightly different behaviour, extending towards the bottom of the ATP pocket, rather than towards the adjacent protomer, resulting in null $\Delta \Delta \mathrm{G}$ values for Arg635, whereas Ile656 and Asn660 had higher $\Delta \Delta \mathrm{G}$ values in relation to the above mentioned protomers. Being Thr525, Leu526 and Thr688 constantly involved in the interaction with the molecule in all protomers, it can be pointed out that the shifting between the two poses occurred around Thr525, acting as a hinge, with NMS-322 sliding between Thr525 and Leu526, allowing a deeper interaction inside the pocket or with the residues from the adjacent protomer.

In order to evaluate the NMS-322 displacement in the different protomers, the average RMSD on the molecule was calculated, after aligning the D2 domain backbone, with respect to the starting structure. The molecules bound to protomers $\mathrm{A}, \mathrm{B}, \mathrm{D}$ and $\mathrm{E}$ show an average RMSD over time of $3.82 \AA, 2.92 \AA, 3.45 \AA$ and $3.30 \AA$, respectively, whereas the average RMSD rose to $5.93 \AA$ and $4.71 \AA$ for the molecules bound to protomers $\mathrm{C}$ and $\mathrm{F}$, respectively. Despite the higher displacement for the molecule bound to protomer $\mathrm{C}$, its $\Delta \mathrm{G}$ of binding $(-47.4 \pm 3.8 \mathrm{kcal} / \mathrm{mol})$ was consistent with the $\Delta \mathrm{G}$ calculated for the molecules bound to protomers A $(-44.4 \pm 3.3 \mathrm{kcal} / \mathrm{mol}), \mathrm{B}(-51.8 \pm$ $3.2 \mathrm{kcal} / \mathrm{mol}), \mathrm{D}(-46.2 \pm 3.0 \mathrm{kcal} / \mathrm{mol})$ and $\mathrm{E}(-53.3 \pm 2.7$ $\mathrm{kcal} / \mathrm{mol}$ ). In this case, NMS-322, as already highlighted by the alanine scanning results, could replace the original interactions with alternative ones, balancing the loss $\Delta \mathrm{G}$ contributions. On the other hand, NMS-322 in protomer $F$ was not found to efficiently rearrange to establish new binding interactions. Calculated $\Delta \mathrm{G}$ of binding within protomer $\mathrm{F}$ and NMS-322 increased to $-38.3 \mathrm{kcal} / \mathrm{mol}$.

Covalent and specific class of inhibitors. NMS-859 is an irreversible protein modifier that was found by mass spectroscopy to covalently and specifically bind VCP at an active site cysteine. The Cys522 residue belongs to the Walker A motif, which is the ATP phosphate binding loop of the D2 domain nucleotide binding site. This covalent modification has been experimentally shown to totally impair the ATPase activity of the enzyme.

A possible mechanism of action would involve the binding of NMS-859 within the ATP binding site on the D2 domain, followed by the formation of a covalent bond with Cys522. In order to study the first step of the proposed binding process and evaluate the non-covalent fitting with the putative binding site, NMS-859 was docked in the D2 domain ATP pocket in the hexameric model (stoichiometry 1:1) and simulated for 20 ns. NMS-859 showed several similarities with NMS-322, primarily a significant contribution to the binding by hydrophobic contacts within the ATP site residues and the adjacent protomer. Computational alanine scanning performed on the last $10 \mathrm{~ns}$ of the trajectory highlighted Leu526, with an average $\Delta \Delta \mathrm{G}$ of $1.6 \mathrm{kcal} / \mathrm{mol}$ and Thr688 $(\Delta \Delta \mathrm{G}=1.6 \mathrm{kcal} /$ $\mathrm{mol}$ ) as hot-spots in all six protomers (Figure $2 \mathrm{c}$ ). The two 
residues made up a hydrophobic cluster with the benzothiazole and phenyl moieties of NMS-859. Ile656, which was identified as a possible partner of interaction for NMS322 , was also found to contribute to the binding with NMS-859 in all the protomers with an average $\Delta \Delta \mathrm{G}$ of 2.1 $\mathrm{kcal} / \mathrm{mol}$. The interaction with residues from the adjacent protomer also played a key role in the binding, in particular through Arg635, with an average $\Delta \Delta \mathrm{G}$ of $1.1 \mathrm{kcal} / \mathrm{mol}$. NMS-859 adopted slightly different poses in the six protomers, resulting in $\Delta \mathrm{G}$ values ranging from $-34.4 \pm$ $2.7 \mathrm{kcal} / \mathrm{mol}$ (protomer E) to $-44.9 \pm 2.0 \mathrm{kcal} / \mathrm{mol}$ (protomer A), as observed for NMS-322. NMS-859 enters the space between Leu526 and Thr688 allowing the molecule to interact more favourably with the hydrophobic residues located at the bottom of the ATP pocket or with Arg635 of the adjacent protomer (as observed for NMS322). Overall, the ligand showed a good affinity for the ATP pocket with the chlorine atom preferentially oriented towards the Walker A loop, possibly representing a favourable molecular arrangement for the reaction with Cys522.

The structural model of NMS-859 covalently bound to the Cys522 sidechain was obtained as described in the material and methods section.
A qualitative analysis of the trajectory highlighted a binding pose comparable to non-covalently bound NMS859. Obviously, an evaluation of the free energy of binding was excluded, given the covalent bonding with the protein. The analysis of residues in proximity of NMS-859 highlighted some of the same amino acids seen for the unbound molecule as possible partners of hydrophobic interactions. In particular, Leu526, Asn660 and Thr688 remained in close contact with the benzothiazole and phenyl moieties of the molecule throughout the entire length of simulations in all six protomers (Figure 2d). Ile656 and Ile479 also contributed in stabilizing the binding with the benzothiazole part of NMS-859.

In a way similar to NMS-322, the Walker A motif provided a series of hydrogen bonds, in particular Lys 524 and Thr 525 backbone ( $41 \%$ and $48 \%$ of the snapshots, respectively) interacts with the amide group and the sulphur of NMS-859. A translation within the pocket, such as observed for the unbound molecule and for NMS-322, is also observed in the covalently bound NMS-859, in this case occurring by the pivoting of the ligand around Cys522. The molecules bound to protomers A and B preserved a pose close to the starting conformation, interact-
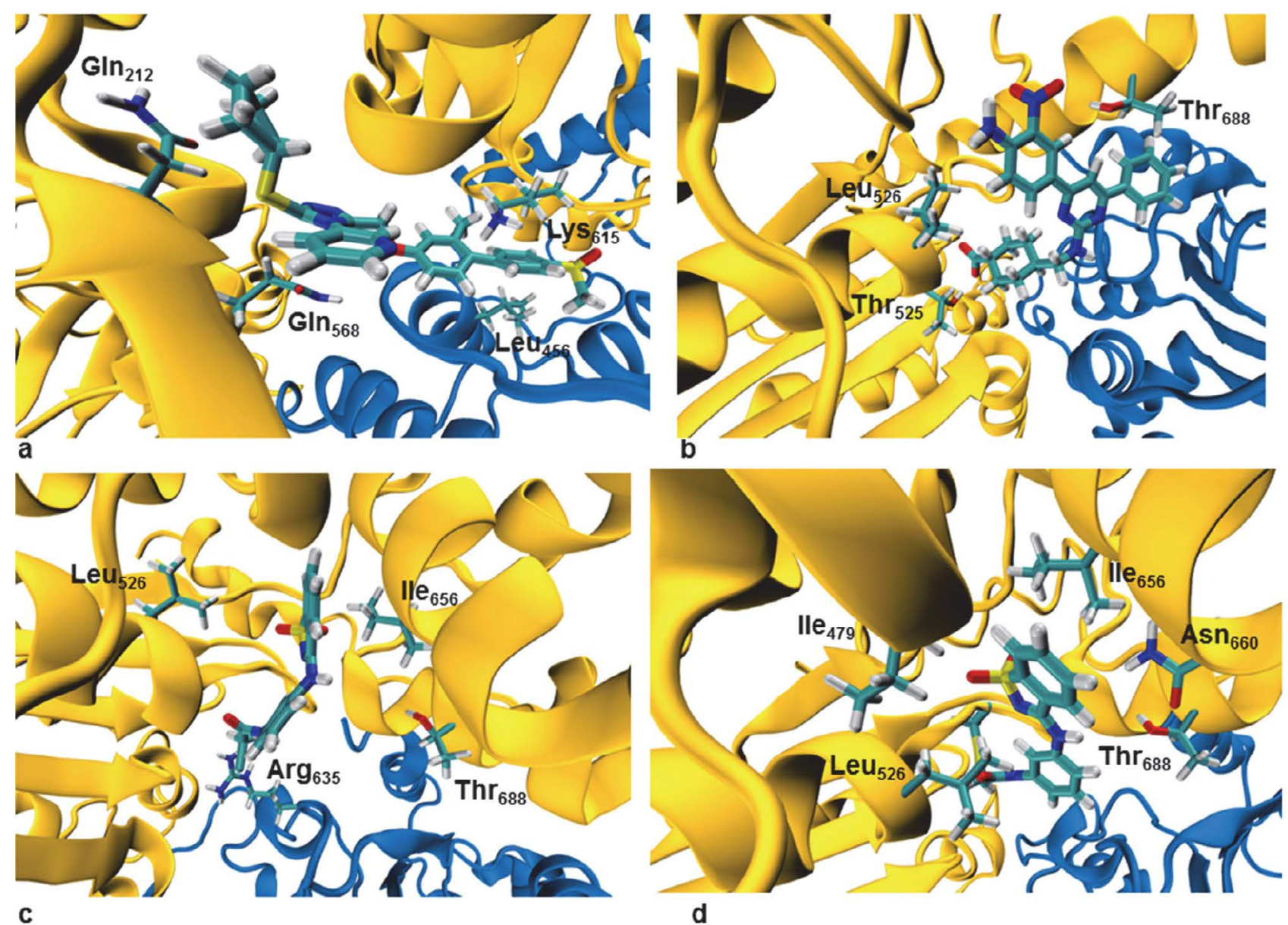

Figure 2a) NMS-873 in complex with p97. b) NMS-322 in complex with p97. c) NMS-859 in complex with p97. d) NMS-859 covalently bound to residue Cys522 of p97. Interaction diagrams of these compounds can be found in Supporting information. 
ing preferentially with residues belonging to the ATP pocket. The average RMSD (calculated on the molecule after the alignment of the $\mathrm{D} 2$ domain) resulted to be 1.04 $\AA$ and $0.83 \AA$, respectively. In these two cases, Thr688 was also favourably oriented to establish a hydrogen bond with the amine hydrogen of NMS-859, detected in 33\% of the snapshots for the molecule bound to protomer A and in $35 \%$ of the snapshots for the molecule bound to protomer B.

For the NMS-859 molecules bound to the protomers C to F, a preferential orientation towards Arg635 and Pro636 of the adjacent protomer was observed. Here the average RMSD with respect to the starting structure were $2.51 \AA$ in protomer $\mathrm{C}, 4.21 \AA$ in protomer $\mathrm{D}, 2.45 \AA$ in protomer E and $2.57 \AA$ in protomer F. In these cases, the loss of interactions with the inner residues of the ATP pocket was presumably balanced by a gain in hydrophobic interactions between Arg635 and Pro636 with the phenyl and thiomethylene moieties of NMS-859, as highlighted for NMS-322.

\section{Conclusions}

The simulations reported in the study reproduce experimental observations made for what concerns both general aspects of molecular stability of the p97 protein and specific molecular interactions with inhibitors. The biologically relevant hexameric assembly was more stable than the dimer and the most unstable part of the single protomer was represented by the D2 domain as observed in crystallographic structures and in trypsin protein digestion experiments. Simulations performed on the different protein-inhibitor complexes showed good stability and reproducibility all around the hexamer. In particular, the postulated allosteric binding site and the binding mode of NMS-873 were surprisingly well conserved throughout the MD trajectory and consistently reproduce some of the most important interactions observed experimentally. Even though the ability to design more potent inhibitors remains to be proven, the approach adopted is certainly useful in providing a dynamic structural model able to rationalize a number of experimental observations regarding the mechanism of action of the different classes of $\mathrm{p} 97$ inhibitors reported to date.

\section{References}

1. B. DeLaBarre, A. T. Brunger, Nat. Struct. Mol. Biol., 2003, 10, 856-863. DOI:10.1038/nsb972

2. D. Nowis, E. McConnell, C. Wojcik, Exp. Cell. Res., 2006, 312, 2921-32. DOI:10.1016/j.yexcr.2006.05.013

3. P. Ballar, S. Fang, Biochem. Soc. Trans., 2008, 36, 818-822. DOI:10.1042/BST0360818

4. C. Wojcik, M. Rowicka, A. Kudlicki, D. Nowis, E. McConnell,
M. Kujawa, N. De Martino, Mol. Biol. Cell., 2006, 17, 46064618. DOI:10.1091/mbc.e06-05-0432

5. B. Medicherla, A. L. Goldberg, J. Cell. Biol., 2008, 182, 663-73. DOI:10.1083/jcb.200803022

6. X. Zhang, A. Shaw, P. A. Bates, R. H. Newman, B. Gowen, E. Orlova, M. A. Gorman, H. Kondo, P. Dokurno, J. Lally, G. Leonard, H. Meyer, M. Heel, P. S. Freemont, Molecular cell, 2000, 6, 1473-1484. DOI:10.1016/S1097-2765(00)00143-X

7. P. Magnaghi, R. D’alessio, B. Valsasina, N. Avanzi, S. Rizzi, D. Asa, F. Gasparri, L. Cozzi, U. Cucchi, C. Orrenius, P. Polucci, D. Ballinari, C. Perrera, A. Leone, G. Cervi, E. Casale, Y. Xiao, C. Wong, D. J. Anderson, A. Galvani, D. Donati, T. O’Brien, P. K. Jackson, A. Isacchi, Nat. Chem. Biol., 2013, 9, 548-556. DOI: $10.1038 /$ nchembio. 1313

8. P. Polucci, P. Magnaghi, M. Angiolini, D. Asa, N. Avanzi, A. Badari, J. Bertrand, E. Casale, S. Cauteruccio, A. Cirla, L. Cozzi, A. Galvani, P. K. Jackson, Y. Liu, S. Magnuson, B. Malgesini, S. Nuvoloni, C. Orrenius, F. R. Sirtori, L. Riceputi, S. Rizzi, B. Trucchi, T. O’Brien, A. Isacchi, D. Donati, R. D’Alessio, J. Med. Chem., 2013, 56, 437-450.

DOI: $10.1021 / \mathrm{jm} 3013213$

9. G. Cervi, P. Magnaghi, D. Asa, N. Avanzi, A. Badari, D. Borghi, M. Caruso, A. Cirla, L. Cozzi, E. Felder, A. Galvani, F. Gasparri, A. Lomolino, S. Magnuson, B. Malgesini, I. Motto, M. Pasi, S. Rizzi, B. Salom, G. Sorrentino, S. Troiani, B. Valsasina, T. O’Brien, A. Isacchi, D. Donati, R. D’Alessio, J. Med. Chem., 2014, 57, 10443-10454. DOI:10.1021/jm501313x

10. F. Dapiaggi, S. Pieraccini, D. Potenza, F. Vasile, H. Macut, S. Pellegrino, A. Aliverti, M. Sironi, New J. Chem., 2017, 41, 4308-4315. DOI:10.1039/C6NJ04014D

11. F. Dapiaggi, S. Pieraccini, M. Sironi, Mol. BioSyst., 2015, 11, 2152-2157. DOI:10.1039/C5MB00348B

12. C. Marucci, M. S. Christodoulou, S. Pieraccini, M. Sironi, F. Dapiaggi, D. Cartelli, A. M. Calogero, G. Cappelletti, C. Vilanova, S. Gazzola, G. Broggini, D. Passarella, Eur. J. Org. Chem., 2016, 11, 2029-2036.

DOI:10.1002/ejoc.201600130

13. M. S. Christodoulou, F. Zunino, V. Zuco, S. Borrelli, D. Comi, G. Fontana, M. Martinelli, J. B. Lorens, L. Evensen, M. Sironi, S. Pieraccini, L. Dalla Via, O. M. Gia, D. Passarella, ChemMedChem, 2012, 7, 2134-2143.

DOI:10.1002/cmdc.201200322

14. E. Krissinel, K. Henrick, J. Mol. Biol., 2007, 372, 774-797. DOI:10.1016/j.jmb.2007.05.022

15. The PyMOL Molecular Graphics System, Version 2.0 Schrödinger, LLC.

16. A. Sali, T. L. Blundell, J. Mol. Biol., 1993, 234, 779-815. DOI:10.1006/jmbi.1993.1626

17. B. Hess, C. Kutzner, D. V. D. Spoel, E. Lindahl, J. Chem. Theory Comput., 2008, 4, 435-447. DOI:10.1021/ct700301q

18. K. Lindorff-Larsen, S. Piana, K. Palmo, P. Maragakis, J. L. Klepeis, R. O. Dror, D. E. Shaw, Proteins: Struct., Funct., Bioinf., 2010, 78, 1950-1958.

19. J. Wang, R. M. Wolf, J. W. Caldwell, P. A. Kollman, D. A. Case, J. Comput. Chem., 2004, 25, 1157-1174.

DOI:10.1002/jcc.20035 
20. W. L. Jorgensen, J. Chandrasekhar, J. D. Madura, R. W. Impey, M. L. Klein, J. Chem. Phys., 1983, 79, 926-935. DOI:10.1063/1.445869

21. G. Bussi, D. Donadio, M. Parrinello, J. Chem. Phys., 2007, 126, 141011-141017. DOI:10.1063/1.2408420

22. T. Darden, D. York, L. Pedersen, J. Chem. Phys., 1993, 98, 10089-10092. DOI:10.1063/1.464397

23. B. Hess, H. Bekker, H. J. Berendsen, J. G. Fraaije, J. Comput. Chem., 1997, 18, 1463-1472.

DOI:10.1002/(SICI)1096-987X(199709)18:12<1463::AIDJCC4>3.0.CO;2-H

24. H. J. Berendsen, J. P. M. van Postma, W. F. van Gunsteren, A. R. H. J. DiNola, J. R. Haak, J. Chem. Phys., 1984, 81, 36843690. DOI:10.1063/1.448118

25. I. Massova, P. A. Kollman, Perspect. Drug Discovery Des., 2000, 18, 113-135. DOI:10.1023/A:1008763014207
26. D. Spiliotopoulos, A. Spitaleri, G. Musco, PloS one, 2012, 7, e46902. DOI:10.1371/journal.pone.0046902

27. R. T. Bradshaw, B. H. Patel, E. W. Tate, R. J. Leatherbarrow, I. R. Gould, Protein Eng., Des. Sel., 2010, 24, 197-207. DOI:10.1093/protein/gzq047

28. S. P. Brown, S. W. Muchmore, J. Med. Chem., 2009, 52, 31593165. DOI:10.1021/jm801444x

29. G. Saladino, S. Pieraccini, S. Rendine, T. Recca P. Francescato, G. Speranza, M. Sironi, JACS, 2011, 133, 2897-2903. DOI:10.1021/ja105030m

30. M. E. Crisan, P. Bourosh, M. E. Maffei, A. Forni, S. Pieraccini, M. Sironi, Y. M. Chumakov, PLoS ONE, 2014, 9, e101892. DOI:10.1371/journal.pone.0101892

31. C. McMartin, R. S. Bohacek, J. Comput.-Aided Mol. Des., 1997, 11, 333-344.

DOI:10.1023/A:1007907728892

\section{Povzetek}

Izvedli smo simulacije molekulske dinamike za binarne (kompleks nukleotid-dimer in heksamer proteina) in ternarne (kompleks nukleotid-inhibitor proteina) komplekse proteina p97, da bi razumeli stabilnost domene oligomera p97 in, kar je še bolj pomembno, molekularne mehanizme v inhibiciji, vključno z različnimi alosteričnimi, ATP-kompetitivnimi in kovalentnimi inhibitorji, o katerih so poročali kratkim. Analiza stabilnih stanj, ki sledijo uravnoteževalnim fazam, je pokazala, da je homoheksamer bolj stabilen v primerjavi z dimerom, in hkrati so domene N-D1 bolj stabilne v pirmerjavi $\mathrm{z}$ domeno D2. Molekulska dinamika predlaganega alosteričnega vezavnega modela reproducira pomembne molekulske interakcije, ki so bile ugotovljene eksperimentalno z visoko frekvenco vzdolž trajektorije. Opažene konformacijske spremembe, ki se pojavljajo v D2-vezavnem mestu nukleotidov, ponujajo novo hipotezo, imenovano bind-rearrange-react, o postopnih molekularnih dogodkih, ki so udeleženi pri specifičnem kovalentnem načinu delovanja inhibitorjev. 